\title{
ELECTRON SPIN RESONANCE OF IRRADIATED DNA
}

\author{
P. S. PERSHAN*, R. G. SHULMAN, B. J. WYLUDA and J. EISINGER \\ Bell Telephone Laboratories, Inc., Murray Hill, New Jersey
}

(Received 6 November 1964)

\begin{abstract}
An electron spin resonance study of deoxyribonucleic acid (DNA) after irradiation with U.V. light or ionizing radiation has identified the main free radical as a hydrogen addition product of the base thymine. The unpaired spin has been located at the $C_{5}$ position from its hyperfine interaction of $20.8 \pm 0.3$ gauss with the $-\mathrm{CH}_{3}$ group attached to $\mathrm{C}_{5}$ and confirmed by deuteration of the methyl group. Hydrogen atom addition at the $\mathrm{C}_{6}$ was proven by exposing the $\mathrm{DNA}$ to $\mathrm{D}_{2} \mathrm{O}$ vapors before irradiation in which case the $37.76 \mathrm{hfs}$ of the $\mathrm{CH}_{2}$ was reduced to the value characteristic of $\mathrm{CHD}$. The amount of water vapor increased the amount of thymine radical as did increasing the intensity of irradiation and the sample temperature during irradiation from $77^{\circ}$ to $195^{\circ} \mathrm{K}$. The quantum yield was $\sim 5 \times 10^{-4}$ radicals/photon adsorbed which, within experimental error, is as large as for any stable photoproduct of DNA. Paramagnetic metal ions bound to the $D N A$ in the ratio of one per ten phosphates reduced the amount of free radical formed by a factor of about six. Denaturing the DNA does not change the resonances observed. DNA from different animals shows different amounts of the thymine radical and these differences are not understood. It is not known what stable photoproduct is formed by the thymine radical when it disappears at room temperature in moist samples. Four other radicals are characterized, but not identified, by subtracting the calculated thymine spectrum from the observed spectra.
\end{abstract}

\section{Introduction}

GENETIC information is contained in the sequence of bases in the deoxy ribonucleic acid (DNA) molecule. The molecule consists of a double helix [1] with two sugar-phosphate chains describing the helices held together by four bases whose complementary hydrogen bonds specifically pair the base adenine with thymine and the base guanine ith cytosine. Since Muller's [2] irradiation of fruit flies with X-rays, it has been known that radiation causes mutations, while since the experiments of Avery et al. [3] it has been known that DNA is the molecular equivalent of the gene. As might be expected from these facts, radiation damage of DNA had been studied intensively by many techniques including Electron Spin Resonance (ESR) before we began this investigation. However, the unique ability of an ESR experiment to detect free radicals and to identify them from their hyperfine interaction with their environment had not been used to identify free radicals in DNA. Although DNA molecules in vivo have a molecular weight of $\sim 10^{8}$, from the viewpoint of an ESR experiment DNA can be considered as a collection of six different small molecules, i.e. the four bases, the sugar and the phosphate. These smaller molecules contain from four to

*Present address: Alfred P. Sloan Fellow, on leave from the Division of Engineering and Applied Physics, Harvard University, Cambridge, Massachusetts. 
eleven atoms in their skeletons, plus hydrogens, and their spectra offered some promise of interpretation. The earlier ESR results were mainly used to study the amount of damage introduced and an excellent review article is available [4]. Recent review articles are also available on the chemical, genetic and optical $[5,6]$ studies of radiation damage in DN A, fields in which dramatic advances have been made recently. In this paper we shall present the results of our ESR study of radiation damage in DNA which identifies the principal radical formed. Preliminary results $[7,8]$ have already been published while subsequent to our reports, but independently, Ehrenberg et al. [9] had also identified the dominant radical in irradiated DNA as thymine by comparison with Shields and Gordy's [10] investigation of radiation damage in the constituents of the nucleic acids.

\section{Experimental Conditions}

In general, the experiments consisted of irradiating DNA fibers while cold, keeping them cold enough to stabilize the free radicals and observing the ESR spectrum produced by the irradiation. In order to ensure freedom from background resonances, unirradiated control samples were measured. Background resonances were rarely observed and were always negligible. Most measurements were made on Calf Thymus DNA Batch number 606 from Worthington Biochemicals of Freehold, New Jersey. Our previous [11] examination of background ferro-magnetic reson ances from metal ion impurities in DNA samples had shown that Worthington Calf Thymus DN A was particularly clean in this respect, while its viscous behavior in solution indicated rather high molecular weight. Unless otherwise specified, all ESR measurements were made with a Varian Associates X-band spectrometer with $100 \mathrm{kcps}$ modulation on samples maintained at $77^{\circ} \mathrm{K}$.

Ionizing irradiation came from an $1 \mathrm{MeV}$ van de Graaff (where the samples were laid on dry ice and kept as cool as the thermal contact and reducing the dose rate would allow) or from a $\mathrm{Co}^{60}$ source at $\sim 0.5 \mathrm{Mrad} / \mathrm{hr}$ in which the samples were at room temperature. The conditions of U.V. irradiation were a subject of investigation and will be discussed later.

\section{Identification of Thymine Radical}

In this section we shall show that one of the free radicals produced by irradiation is a hydrogen addition product of the constituent base thymine. This radical was easy to identify because its hyperfine structure spread over 135 gauss so that it always extended beyond any other radical present. In Figure 1 are shown the ESR signals observed after irradiation of calf thymus DNA with $10 \mathrm{Mrad}$ of $1.0 \mathrm{MeV}$ electrons and with U.V. light of $\approx 10^{7} \mathrm{ergs} / \overline{\mathrm{mm}}^{2}$ in the DNA absorption bands. Disregarding the central region a close match exists between the two sets of satellite structures - a match which becomes closer on a more quantitative examination. The spread is 135 gauss, in both cases the intervals between the two neighboring outermost lines are $20.8 \pm 0.3$ gauss and their intensity ratios are $3: 1$ for both resonance patterns. In Figure 2(a) and 2(b) the U.V. damage pattern is compared with that from polycrystalline thymine [10] (possibly thymine monohydrate) where these features are repeated. The damage center is postulated to arise from the addition of hydrogen to $C_{6}$ of thymine which breaks the double bond and leaves an unpaired electron on $C_{5}$ as shown in Figure 3(a). In order to fit the experimental pattern, the hf interaction of this electron with the methyl hydrogens is fixed at 20.8 gauss and with the two methylene protons on $\mathrm{C}_{6}$ at 37.7 gauss. The resonance pattern predicted from these parameters is shown in Figure 2(a). It consists of a 1:2:1 triplet with a separation of 37.7 gauss arising from interactions wi the $-\mathrm{CH}_{2}$ protons. Each of these lines is further split in to a quartet with intensity ratios of $1: 3: 3: 1$ by the $-\mathrm{CH}_{3}$ protons. The quartet splitting, observed in thymine, had been tentatively assigned by Shields and Gordy to the methyl group, an assignment with which we agree. They hesitated about assigning the larger splitting, here assigned to the $-\mathrm{CH}_{2}$ group, because at that time splittings that large had not been identified in model compounds. However, before our preliminary report [7], splittings of $\sim 40$ gauss had been observed from the protons of the adjacent methylene group in irradiated benzene [12], cyclohexadiene $[13,14]$ and $N$-methylthymine [15]. 

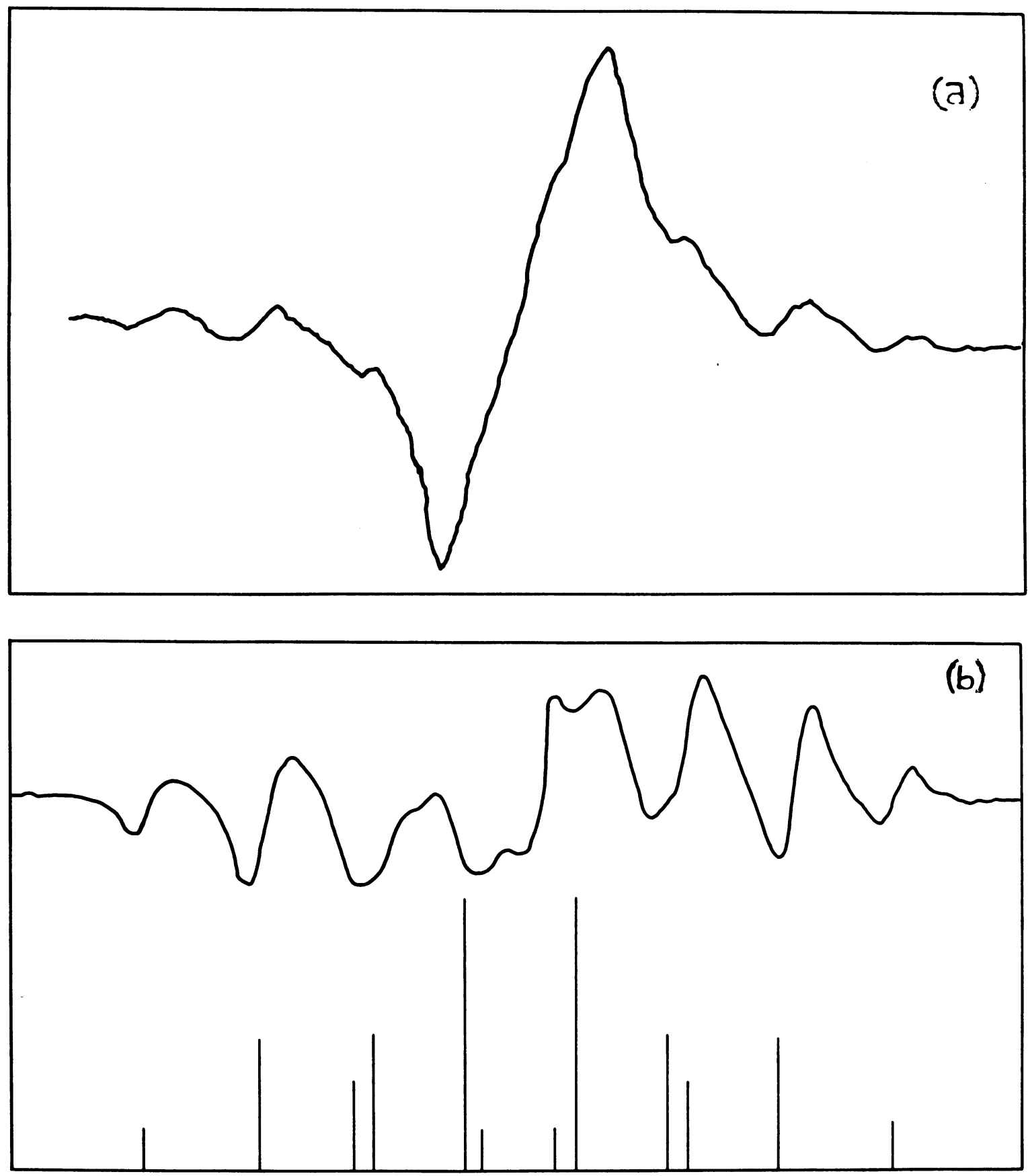

FIGURE 1

A comparison of the ESR signals observed in calf thymus DNA after irradiation by $10 \mathrm{Mrad}$ of $1.0 \mathrm{MeV}$ elec-

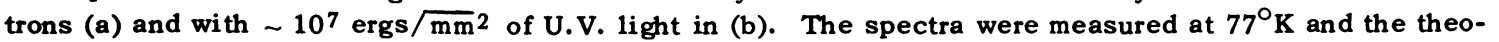
retical pattern for the thymine radical is shown as lines.

The methyl coupling was firmly established through the use of thymine deuterated at the methyl group alone as shown in Figure 3(b). This compound was synthesized by Merck of Canada. Its structure was confirmed by high resolution NMR. The methyl group hfs will be smaller than in the protonated thymine in the ratio of the deuteron to proton nuclear g-factors. The deuteron has spin of one, so instead of four 

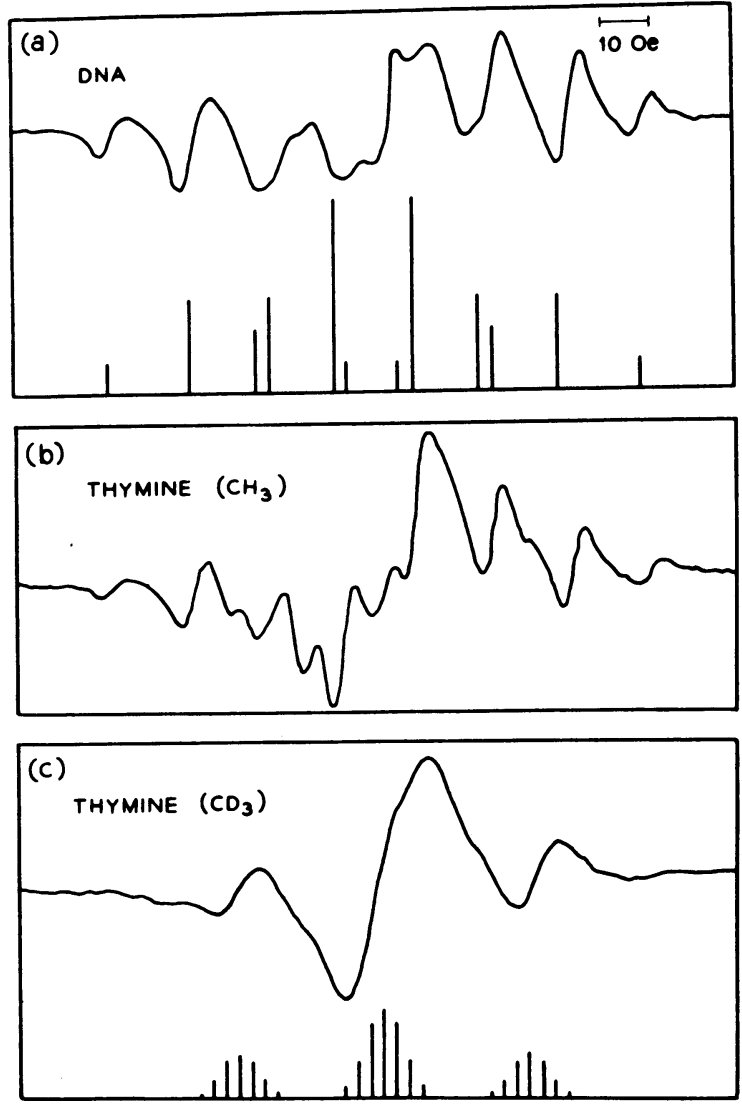

FIGURE 2

(a) ESR from U.V. irradiated calf thymus DNA

(b) ESR from U.V. irradiated poly crystalline thymine

(c) ESR from U.V. irradiated polycrystalline thymine deuterated at the methyl group. The theoretical patterns expected from the models postulated are shown as lines in (a) and (c).

lines the methyl group gives seven unresolved lines. The $-\mathrm{CH}_{2}$ splitting will not be changed, however, and the pattern predicted is shown in Figure 2(c) below the observed one. The agreement is very good and it is obvious that the hf splitting has been considerably simplified.

In order to show that the thymine radical in DNA changes the same way upon deuteration, we grew the thymine requiring bacteria $E$. coli $15 T^{-}$. This bacterium is a mutant which has lost the ability to synthesize its own thymine but has the ability to incorporate thymine from its growth medium. It was grown in a synthetic medium containing glucose, inorganic salts and thymine. Two separate batches were grown, one with the regular thymine and the other with the partially deuterated. A 24-hr period growth was required because of the slower rate of reproduction of the mutant and the resulting concentration of bacteria was $\sim 10^{9} / \mathrm{cc}$ as judged from turbidity, definitely beyond log phase growth. The cells were harvested and the DNA extracted by following Marmur's [16] procedure. About $20 \mathrm{mg}$ of normal and deuterated DNA were obtained and $\sim 5 \mathrm{mg}$ of each were irradiated at $77^{\circ} \mathrm{K}$ by U.V. light. The ESR signals obtained are shown in Figures 4(a) and (b). Although the relative amount of the thymine radical is small compared to the center line (this is reproducible for DNA extracted from $E$. coli as discussed below), it is clear that the elaborate thymine radical $\mathrm{hfs}$ of the control sample has been converted to the satellite pair characteristic of deuterated thymine in the deuterated sample. From these results we conclude that the outer satellite structure in DNA and thymine arise from an electron whose hf interaction with the methyl protons of thymine is 20.8 gauss. 
<smiles>Cc1ccc(C)c(=O)[nH]c1=O</smiles>

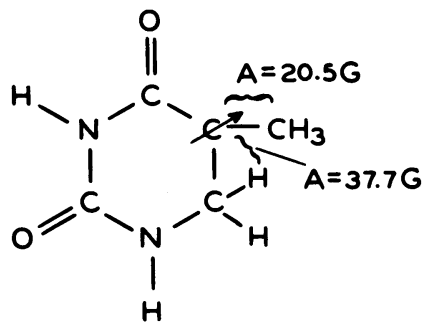<smiles>CCC(=O)c1c[nH]c(=O)[nH]c1=O</smiles>

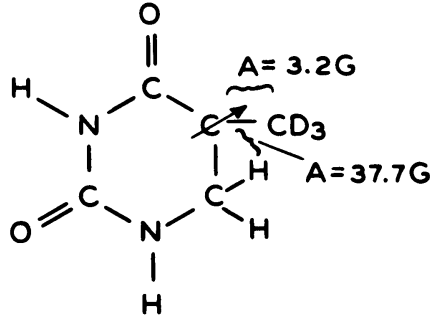

FIGURE 3

Free radical formed in thymine by radiation. Experimental values of the hf coupling constants are given for normal thymine in (a) and extrapolated to the $-\mathrm{CD}_{3}$ case in (b). In DNA the bottom nitrogen is connected to the $C_{1}^{\prime}$ of the ribose.

Now we turn to the postulated hf interaction of 37.7 gauss wi th the two protons at $\mathrm{C}_{6}$. Up to this point the outermost satellites have been shown to arise from the methyl group at $\mathrm{C}_{5}$. Since the center of the resonance pattern is complicated by the presence of other radicals, it was difficult to extricate the theoretical pattern expected from the thymine radical in this region. Preferential annealing experiments, to be described below, were able to remove some of these other resonances from the center region, and helped to establish that the thymine radical spectrum was indeed found in the center. In order to show that a hydrogen does add and also in order to indicate the origin of this hydrogen the following deuteration experiment was performed.

Calf Thymus DNA was dried first at room temperature and then at $85^{\circ} \mathrm{C}$ for $24 \mathrm{hrs}$ under forepump vacuum in order to remove as much water of hydration as possible. Drying the DNA leads to a denaturation which is reversed when moisture is added [17]. Heating the dry DNA to $85^{\circ} \mathrm{C}$ seems to have no irreversible effect on the resonances. Two aliquots were allowed to equilibrate at $25^{\circ} \mathrm{C}$ with $\mathrm{H}_{2} \mathrm{O}$ and $\mathrm{D}_{2} \mathrm{O}$ vapors, respectively, at relative humidities near 100 per cent. One dry sample and the two moistened samples were irradiated with U.V. at the same dose rate for the same time and the resulting ESR spectra, measured at $77^{\circ} \mathrm{K}$, are shown in Figure 5. Notice first that in the dried sample the amount of thymine radical is smaller than in the others. This will be discussed in more detail below. In Figure $5(\mathrm{~b})$ the $\mathrm{H}_{2} \mathrm{O}$ sample has a thymine radical which fits the predicted pattern very well. The sample moistened with $\mathrm{D}_{2} \mathrm{O}$ has a different resonance pattern than the sample moistened with $\mathrm{H}_{2} \mathrm{O}$ and confirms that a deuteron, instead of a proton, has been added at the $\mathrm{C}_{6}$ position of thymine because we observe a pattern caused by a -CHD group instead of $-\mathrm{CH}_{2}$. In a later section the experimental curve is shown to coincide very well with a calculated -CHD curve. The predicted separation between the center of the outermost lines is 100.1 gauss in agreement with the experiment. The agreement for the two outermost lines on both the high and low field sides is excellent and confirms the model. To deuterate the exchangeable protons in DNA, the deuterated sample must be protected from the atmosphere. Exposing it to the atmosphere for a very short time, of the order of $1 \mathrm{~min}$, will allow the deuterium to be exchanged for hydrogen. 

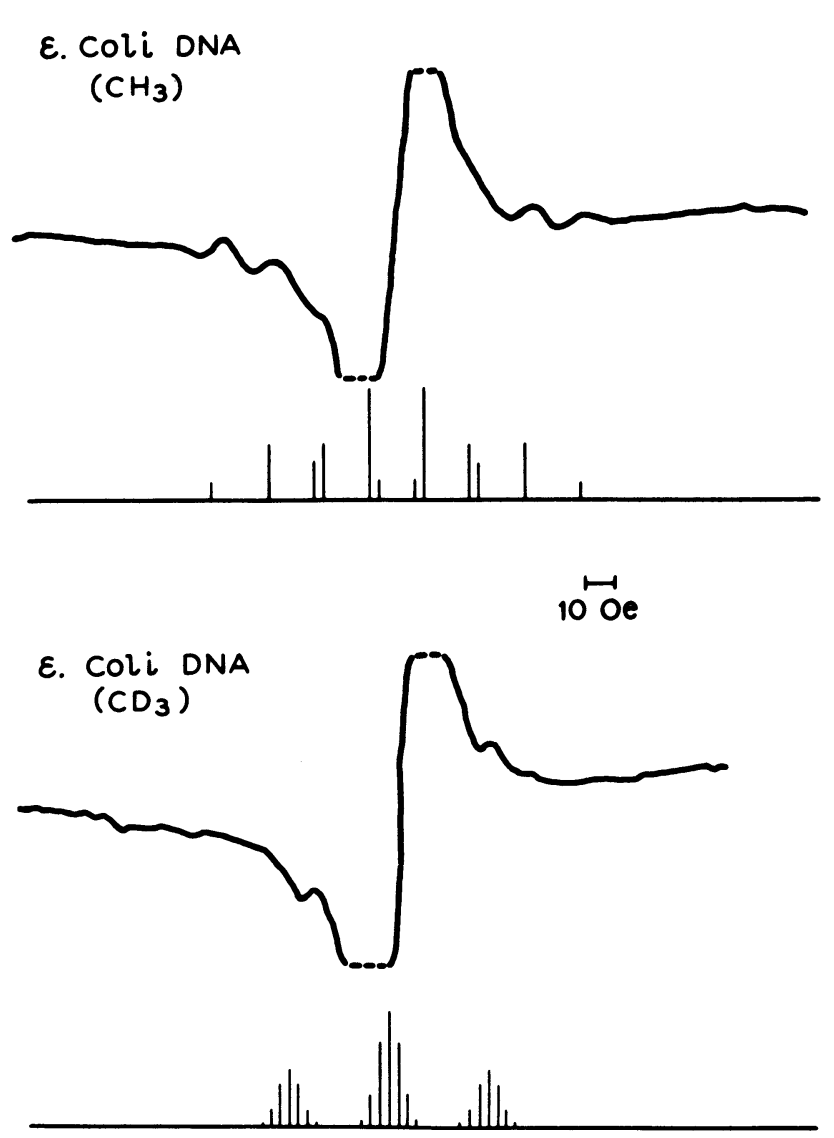

FIGURE 4

The ESR signals observed in E. coli $15 T^{-}$DNA after U.V. irradiation. In (a) the bacteria were grown on normal thymine and in (b) upon partially deuterated thymine.
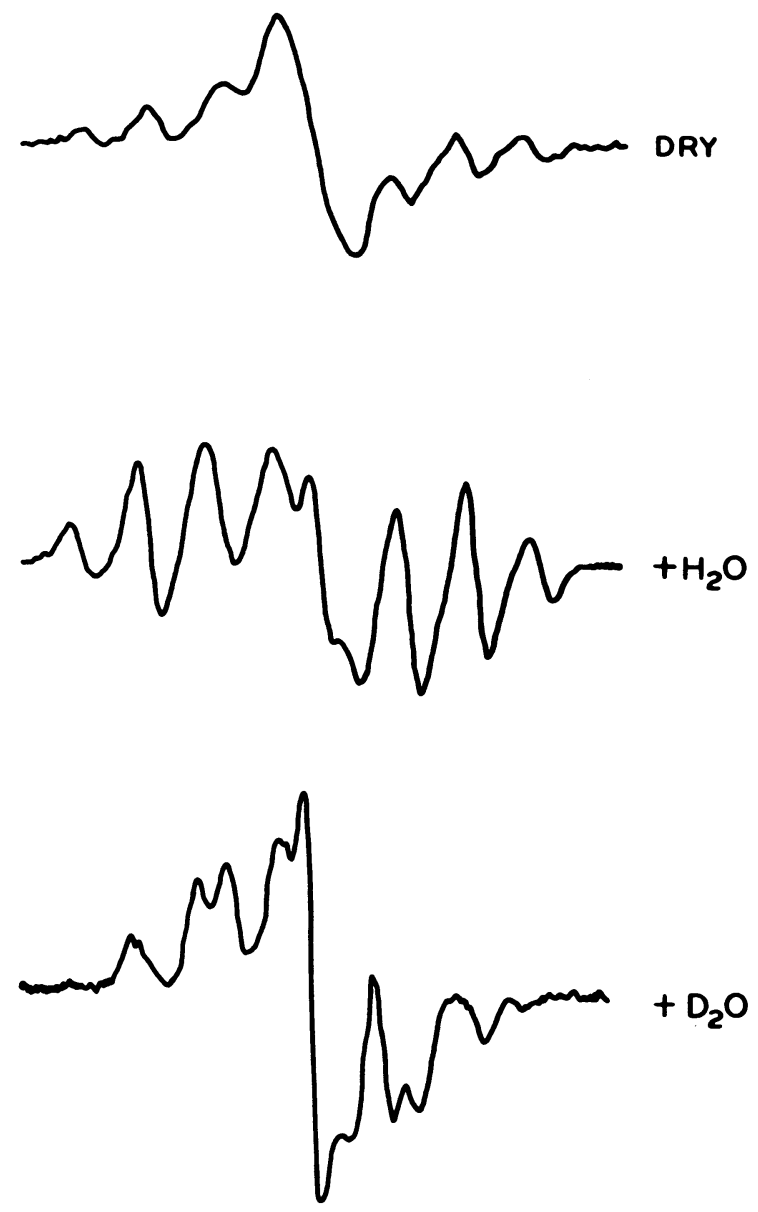

FIGU RE 5

Differences between dry DNA (a), and DNA exposed to 100 per cent Relative Humidity at $25^{\circ} \mathrm{C}$ of $\mathrm{H}_{2} \mathrm{O}$ (b) and $\mathrm{D}_{2} \mathrm{O}$ (c).

\section{Effects of Moisture}

Previous experiments [7] with ionizing irradiation had shown that the resonance signals were quite insensitive to the gas atmosphere - no differences in the radicals formed having been detected between $\mathrm{N}_{2}, \mathrm{O}_{2}$, A and vacuum. However, there clearly was an effect of water vapor upon the stability of the radicals at room temperature. After the ambient gas was shown to have no effect upon the radicals formed, we no longer sealed DNA in tubes but left it exposed to the atmosphere. This worked perfectly well in the winter when the relative humidity in our laboratory was very low $\sim 10$ per cent. However, our surprise was great when we tried to observe resonances in samples which, after irradiation, had been exposed to the atmosphere at room temperature in the summer. No signal was observed.

In order to understand the effects of moisture upon the stability of the radicals at room temperature, we first studied the effects upon the free radicals formed of moistening the DNA before irradiation. The result of a series of experiments designed to show the effects of water vapor upon the resonances is shown in Figure 6. These measurements were all made on samples of $\sim 5 \mathrm{mg}$ dry weight which had been allowed to equilibrate at $25^{\circ} \mathrm{C}$ for $48 \mathrm{hr}$ at different relative humidities, then sealed in quartz tubes and irradiated at $77^{\circ} \mathrm{K}$ with the mercury lamp and the Coming 7-54 filter. Measurements were made at $77^{\circ} \mathrm{K}$ 

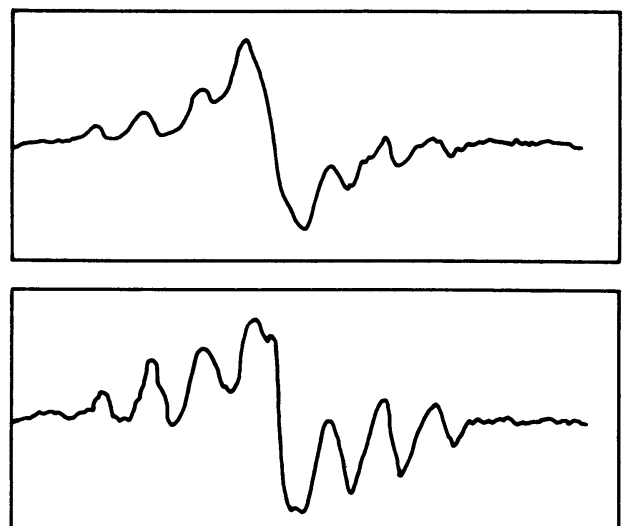

$0 \%$

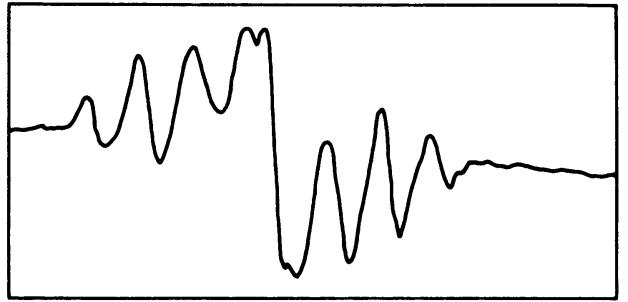

$15 \%$

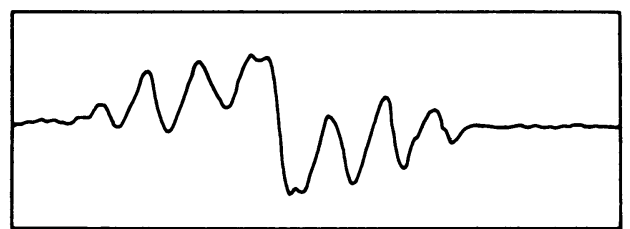

$30 \%$

$51 \%$

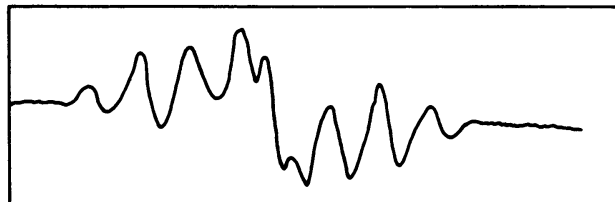

$76 \%$

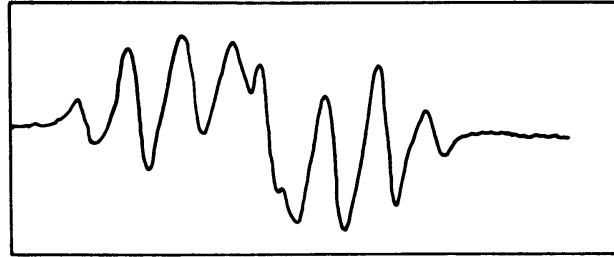

$93 \%$

FIGURE 6

Effects of equilibrating calf thymus DNA with different relative humidities of water vapor at $298^{\circ} \mathrm{K}$ before irradiating and observing the resonances at $77^{\circ} \mathrm{K}$.

without allowing the samples to warm up. The result at 0 per cent relative humidity for calf thymus DNA is extremely reproducible from sample to sample and from month to month. It consists of a small amount of the thymine radical and a broad center line at $g=2$. At higher relative humidities, the thymine signal becomes stronger and the broad center line less obvious. In the moist samples, a sharp center line at $g=2$ which anneals away at $190^{\circ} \mathrm{K}$ is found at $77^{\circ} \mathrm{K}$. It is known that DNA fibers have different crystalline modifications at different relative humidities $[18,19]$. Below about 44 per cent relative humidity, in fact, one cannot observe an X-ray pattern from DNA fibers. There is other [17] evidence that dry DNA is 
at least partially denatured in the sense that a number of interchain hydrogen bonds are broken when the water of hydration is removed. This raised the question as to whether the ESR differences between dry and moist DNA came from the differences in secondary structure or from the different amounts of water available. The ESR signal from heat-denatured DNA fibers which were equilibrated for several days at 75 per cent R.H. is compared in Figure 7 with the signal from native DNA. Because there is no real difference between these signals, the differences in secondary structure are probably not the reasons for the differences between ESR signals from wet and dry native DNA fibers. (In order to obtain these results, it was necessary to expose the two DNA samples to the 75 per cent R.H. solutions for at least two days to enable them to come to equilibrium with the water vapor.) This conclusion tends to imply that energy migration within the DNA molecule does not play an important role in the electronic processes leading to the production of this radical, since energy migration should depend upon the secondary structure.
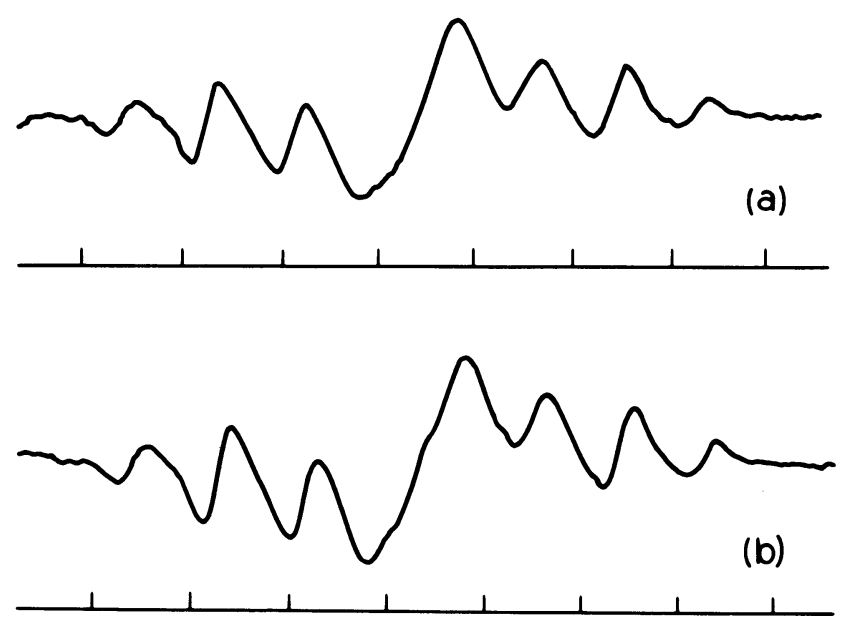

FIGURE 7

A comparison of the ESR signals from native (a) and denatured (b) fibres of calf thymus DNA after each had been equilibrated at 75 per cent $\mathrm{RH}$ at $298^{\circ} \mathrm{K}$ before irradiation.

The main features of the spectra for high relative humidities (i.e., R.H. 75\%) are very reproducible and independent of the source of calf thymus DNA. Calf thymus DNA from different chemical supply houses reproduce these main features with very slight differences. Figure 8 shows the signals from $75 \%$ R.H. calf thymus DNA supplied by Mann, Nutritional Biochemical and Worthington. In all cases the ratio of thymine radical to center radical is greater than in the same samples of DNA when dried. On the other hand, DNA from different species exhibit quantitative differences. Salmon sperm DNA, at 75 per cent R.H. has a smaller ratio of thymine to center signal and the dry salmon sperm DNA has an extremely small thymine signal. The differences in 75 per cent R.H. Seratia Cetals DNA and E. coli DNA are also apparent in Figure 8.

The differences between radicals from different species could arise from physical or chemical variations in the DNA extracted by different techniques. It certainly seems desirable to treat the different DNA's similarly to minimize these possibilities and to see if the differences in the resonances persist. On the other hand, there are important similarities. In all cases the thymine radical is observed with the same hyperfine structure and the effect of drying is to diminish the absolute amount of this radical as well as its intensity relative to the broad center line. Finally, as expected from the original statements about the effect of atmospheric humidity upon the stability of the radicals, we have found that in moist DNA samples the thymine radical is not stable at room temperature while in dry samples it is stable for many hours, decaying somewhat noticeably, but not completely, overnight. 

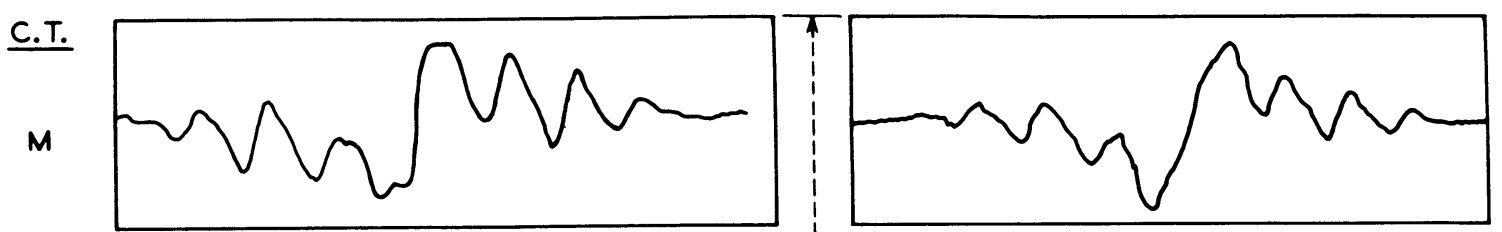

S.S.
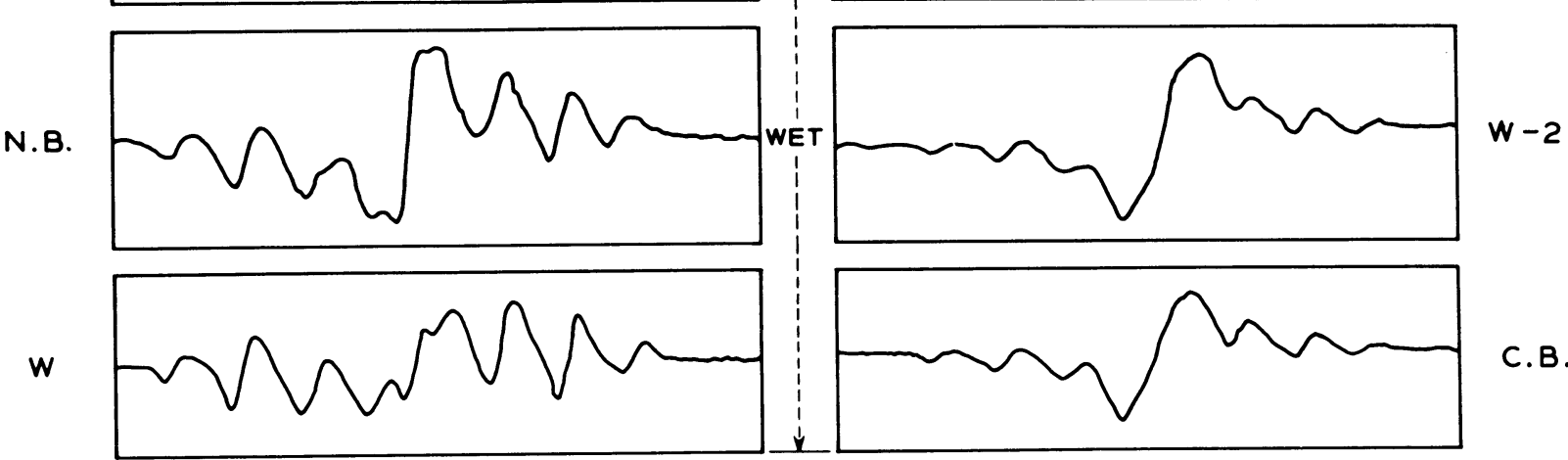

w

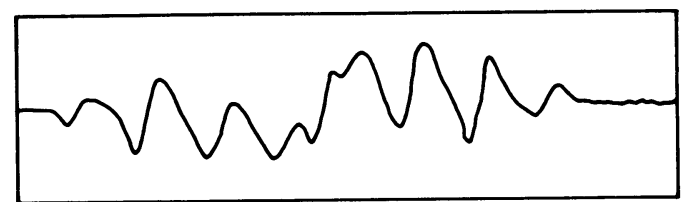

C.B.

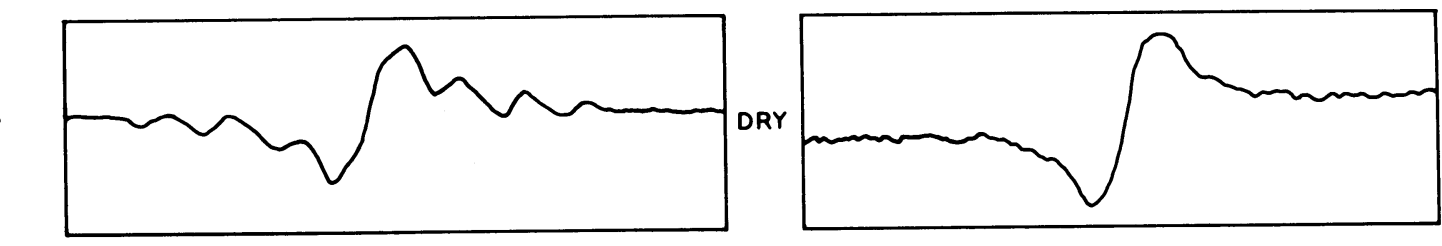

w

W

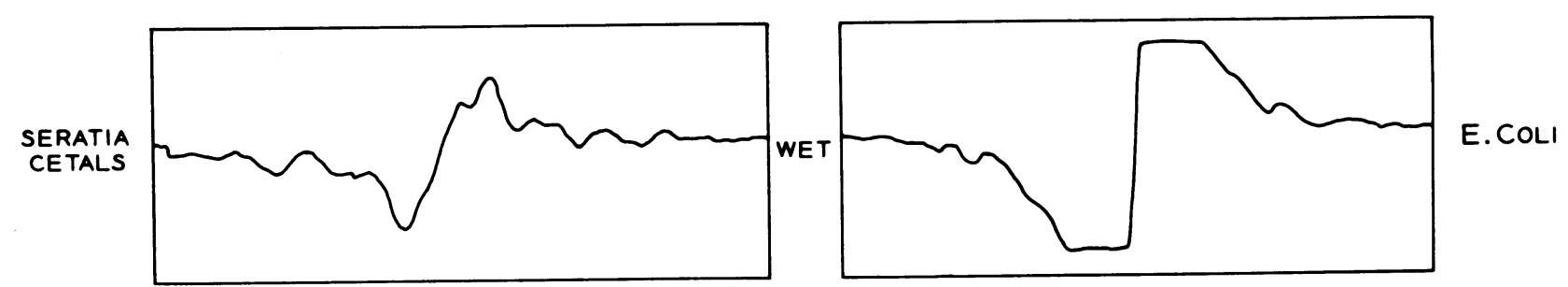

FIGURE 8

Reproducible differences in the relative amounts of thymine radical and center line in DNA from different animals $(\mathrm{CT} \equiv$ calf thymus, $\mathrm{SS} \equiv$ salmon sperm) and different suppliers (M $\equiv$ Mann, N. B. $\equiv$ Nutritional Biochemical, W $\equiv$ Worthington and $\mathrm{CB} \equiv \mathrm{Ca} 1 \mathrm{Biochemica1)}$, which also shows the differences between dry and moist samples of $\mathrm{CT}$ and SS. The bottom two traces are from Seratia Cetals and E. coli bacterium.

\section{Other Radicals in DNA}

Throughout the course of these studies, we have observed many DNA samples. The hyperfine structure spread over 135 gauss is common to all but there are considerable variations in the centers of the resonance patterns. Because under certain conditions samples have spectra which are in excellent agreement wi th the theoretical thymine spectra, we believe that the deviations from the theoretical pattern are caused by other radicals. The other radicals identified in this section are listed in Table 1 .

In moist DNA a narrow line appears at the same g-factor as the thymine radical after U.V. irradiation at $77^{\circ} \mathrm{K}$. This line can be removed by bringing the sample to $195^{\circ} \mathrm{K}$ for several minutes as shown in Figure 9(a), and then returning it to $77^{\circ} \mathrm{K}$ and recording the spectrum. The thymine structure has not changed, as can be seen from the satellites, but the narrow line has been annealed from the center. The difference between these two derivative curves, before and after the $195^{\circ} \mathrm{K}$ anneal, is plotted in Figure 9(b). Some of the narrow center line persists in the annealed sample of Figure 9(a). However, when 
TABLE 1

\begin{tabular}{lcl}
\hline \multicolumn{1}{c}{ g-factor } & $\begin{array}{c}\text { Width of lines } \\
\text { (Gauss) }\end{array}$ & Conditions for observation and annealing \\
\hline 2.0035 & 13 & $\begin{array}{l}\text { Broad center line in dry DNA stable for } \\
\text { many hours at } 298^{\circ} \mathrm{K}\end{array}$ \\
2.0035 & 5 & $\begin{array}{l}\text { Narrow center line in moist DNA which } \\
\text { anneals at } 195^{\circ} \mathrm{K}\end{array}$ \\
$\begin{array}{l}\text { Two lines centered } \\
\text { at } 2.0035\end{array}$ & 7 & $\begin{array}{l}\text { Lines split by } 40 \text { gauss, partially } \\
\text { annealed at } 195^{\circ} \mathrm{K}\end{array}$ \\
2.0035 & 10 & $\begin{array}{l}\text { Center } 1 \text { ine remaining in moist DNA after } \\
195^{\circ} \mathrm{K} \text { anneal } \\
\text { Center line remaining in some moist DNA } \\
\text { samples after } 195^{\circ} \mathrm{K} \text { anneal. Similar to } \\
\text { cytidine. }\end{array}$ \\
\hline
\end{tabular}

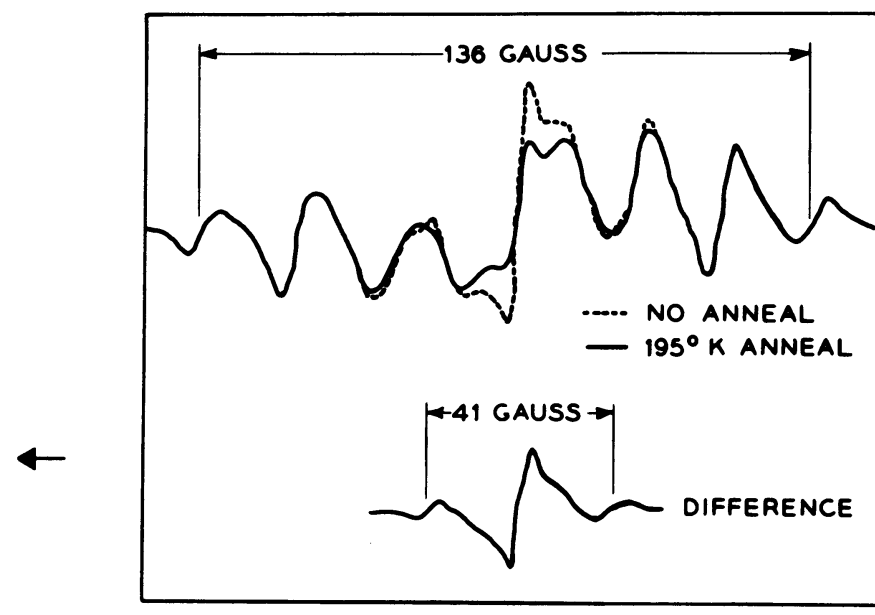

FIGURE 9

(a) A comparison of the ESR signal from a moist calf thymus DNA before and after a several minute anneal at $195^{\circ} \mathrm{K}$

(b) The difference between the two spectra of $10(a)$.

this experiment was repeated on wetter samples, annealed for longer times, all of the narrow center line visible to the eye could be removed at $195^{\circ} \mathrm{K}$. The difference spectrum enables one to determ ine that the width between derivative extrema of the narrow line is 5 gauss. In addition to the narrow center line, two additional lines are partially removed by the $195^{\circ} \mathrm{K}$ anneal. They are symmetrically located on either side of the narrow center line and are separated by 41 gauss. Because they are broader than the narrow center line and are not always found (or annealed) with a relative intensity which is fixed with respect to the narrow central line, we infer that they are not the same radical. It is possible that these two satellites do have a central line but we have no evidence for or against this possibility.

Figure 10 shows the fit between several experimental curves taken after anneal at $195^{\circ} \mathrm{K}$ (solid lines) and the theoretical thymine pattem (broken curves). The horizontal scale varies by about 10 per cent from trace to trace and the theoretical pattern was adjusted for this. The heights of the theoretical curves were normalized to agree with the wings of the experimental curves. The excellent agreement between theory and experiment in the wings is self evident. This is further support for the model of the thymine radical discussed above. 
WET-ANNEALED
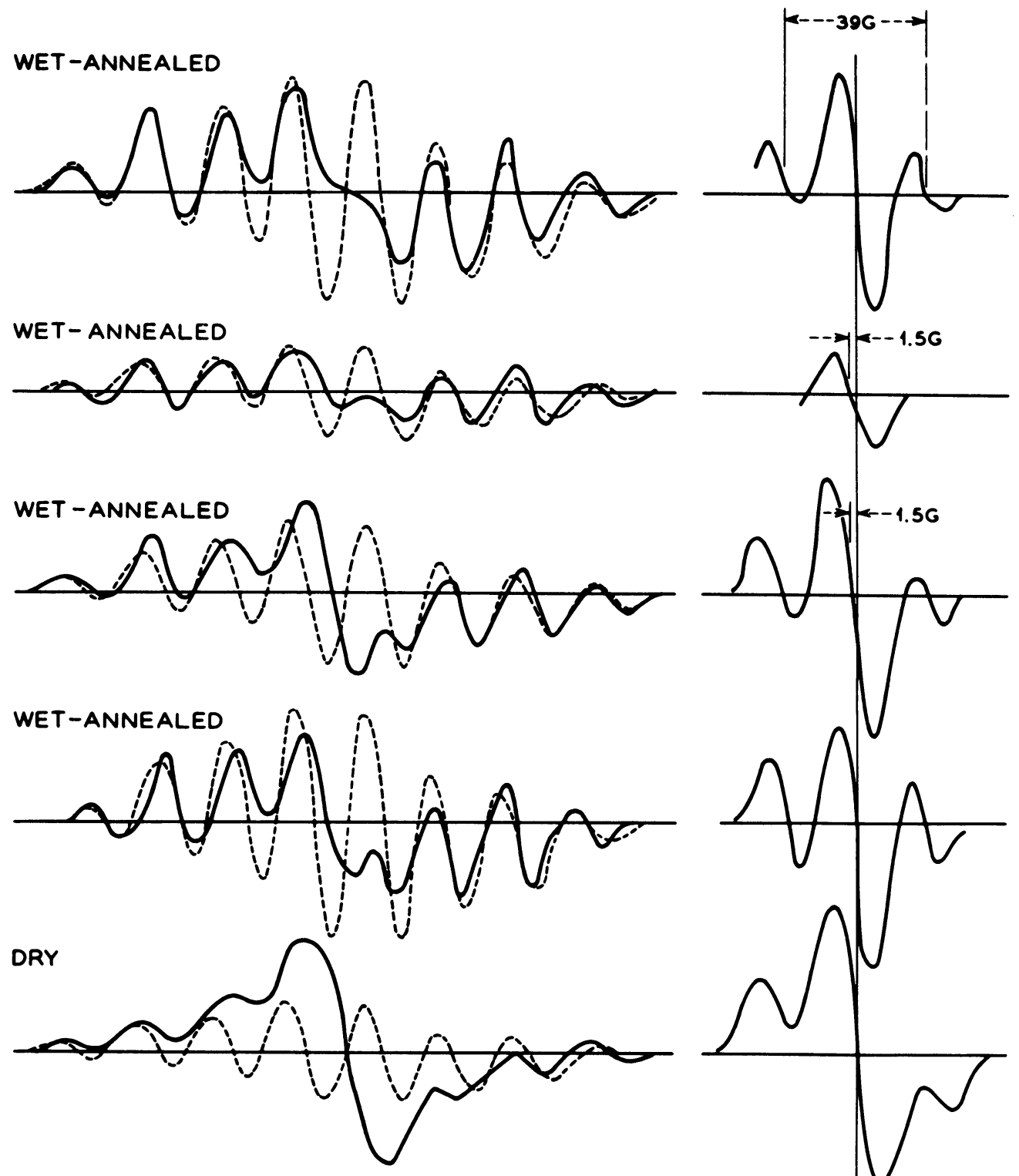

WET $\left(D_{2} O\right)$-ANNEALED

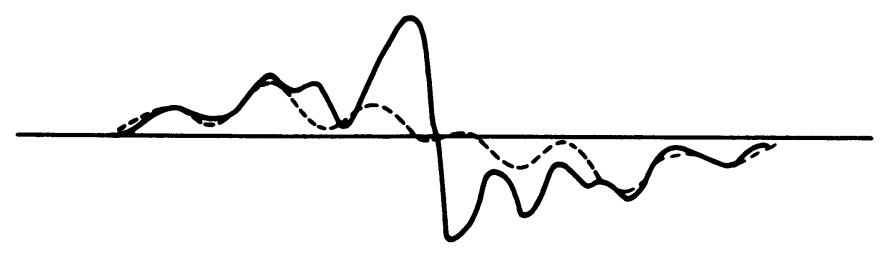

EXPERIMENTAL CURVES

THEORETICAL CURVES

FIGURE 10

Comparison and subtraction of experimental curves and calculated spectra of the thymine radical. The differences, attributed to other radicals, are shown on the right, described in the text and listed in Table 1. 
Note that in the samples moistened with $\mathrm{H}_{2} \mathrm{O}$ the center of the ESR spectra is sometimes symmetric about the center and sometimes asymmetric. The right side of Figure 10 shows the difference between experimental and theoretical curves. Where these differences were small compared to uncertainties in the measurement or in the fit, we have neglected them. The results of the subtraction do not show the asymmetries as clearly as the original experimental curves. Small asymmetries when added to a symmetric spectrum tend to become much more prominent. From Figure 10 we can detect at least three different radicals in addition to thymine in the moist $\mathrm{H}_{2} \mathrm{O}$ samples. There is a symmetric center line, a center line that is either asymmetric or shifted in g-value to lower field and the two lines separated by about 40 gauss to either side of center.

The only clue we have as to the identity of these other radicals concerns the line which is shifted to lower fields. The $g$-factor of the thymine radical is 2.0035 and this other radical, which is shifted by about 2 gauss out of 3200 , has a g-factor of $\sim 2.004$ which agrees fairly well with the spectra Shields and Gordy [10] have observed in cytidine. Future work to separate these radicals might well take advantage of the ease with which one can pull oriented fibers of DNA. Placing $H_{o}$ along the symmetry axis of the fibre should result in the same value of any anisotropic interactions (such as hyperfine fields, crystal field interactions, etc.) and allow determination of the spin Hamiltonian parameters alone one principle axis. Furthermore, since these central lines are unresolved, presumably because the anisotropic hfs is comparable to the isotropic, it is particularly desirable to look for resolution of the $\mathrm{hfs}$ of these lines in oriented fibres. Ehrenberg [20] has reported some success in these directions.

The subtraction in DNA moistened by $\mathrm{D}_{2} \mathrm{O}$ is slightly different from the $\mathrm{H}_{2} \mathrm{O}$ result. Since the difference is comparable to the subtractions obtained from the $\mathrm{H}_{2} \mathrm{O}$ samples, the identification of the radical as -CHD replacing $-\mathrm{CH}_{2}$ is consistent with the experimental curves.

None of the radicals in Figure 10 anneal at $195^{\circ} \mathrm{K}$. Thus, the narrow center line in Figure 9 which disappears at $195^{\circ} \mathrm{K}$ represents another radical. However, the doublet which anneals somewhat at $195^{\circ} \mathrm{K}$ seems very similar to the doublet still remaining after $195^{\circ} \mathrm{K}$ anneal and they will not be distinguished in Table 1 where these resonances are described.

\section{Quantum Efficiency, Wavelength and Temperature Effects}

The standard technique for producing free radicals in DNA with U.V. light was to illuminate a sample $(5-10 \mathrm{mg})$ at $77^{\circ} \mathrm{K}$ with an OSRAM $500 \mathrm{~W}$ high pressure mercury lamp focused on the sample with an 8 in. dia. spherical mirror, which had an 8 in. radius of curvature. The spectral output of this lamp, as shown in Figure 11, cons ists of a peak between 2400 and $2500 \AA$, nothing from 2500 to $2800 \AA$, while most of the energy was at longer wavelengths. There was considerable energy in the visible and infrared, not shown in the figure, which was removed by filters. A Corning 7-54 filter, passing $2400 \rightarrow 4000 \AA$, a $4 \mathrm{~cm} \mathrm{H}_{2} \mathrm{O}$ filter which passes everything but the infrared, and a $4 \mathrm{~cm}$ thick solution of $0.2 \mathrm{M} \mathrm{NiSo}_{4}$ in $\mathrm{H}_{2} \mathrm{O}$, passing 2200 to $3600 \AA$ were used alternately with equivalent results.

The total energy output of the OSRAM lamp in the $2400 \rightarrow 3600 \AA$ region is of the order of several watts. Because of the differences between DNA absorption spectrum and lamp output spectrum, it was necessary to make a direct measurement of the power absorbed in the optically thick DNA fibers which absorbed most of the energy output of the lamp far out in the tail of the absorption band. By measuring the temperature rise in a $100 \mathrm{~g} / 1$. solution of $\mathrm{CuSO}_{4}$ in $\mathrm{H}_{2} \mathrm{O}$, which absorbed all wavelengths shorter than $3200 \AA$ and nothing from 3200 to $4000 \AA$ (Corning 7-54 filter cuts off $\lambda \geq 4000 \AA$ ), we estimated $0.25 \mathrm{~W}$ to be the upper limit of power absorbed by the DNA. Because the Corning 7-54 has a small transmission peak in the neighborhood of $7200 \AA$, where the $\mathrm{CuSO}_{4}$ absorbs, this is surely an upper limit. A $1 \mathrm{mg} / \mathrm{ml}$ solution of thymine, which only absorbed out to $2900 \AA$, absorbed $0.05 \mathrm{~W}$, which can be taken as a lower limit. Calorimetric measurements at the sample position gave the result that an optically thick DNA sample absorbed $0.15 \pm 0.1 \mathrm{~W}$ in the spectral region transmitted by the 7-54 filter (2400-4000 $\AA$ approx.), which agreed with the other determinations.

Taking the mean wavelength to be $3000 \AA, 0.15 \mathrm{~W}$ is equivalent to $2.2 \times 10^{17}$ photons $/ \mathrm{sec}$. With this rate of irradiation for $2 \mathrm{~min}$. on each of two opposite sides of an optically thick bundle of DNA fibers, 


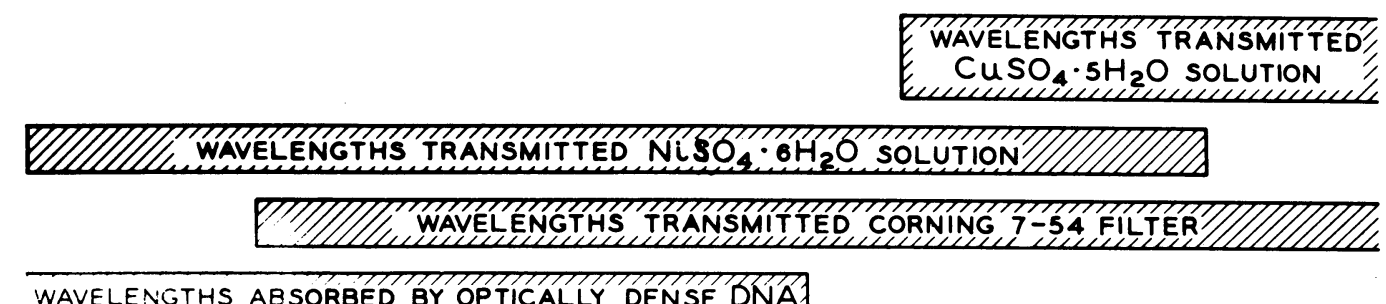

WAVELENGTHS ABSORBED BY OPTICALLY DENSE DNA

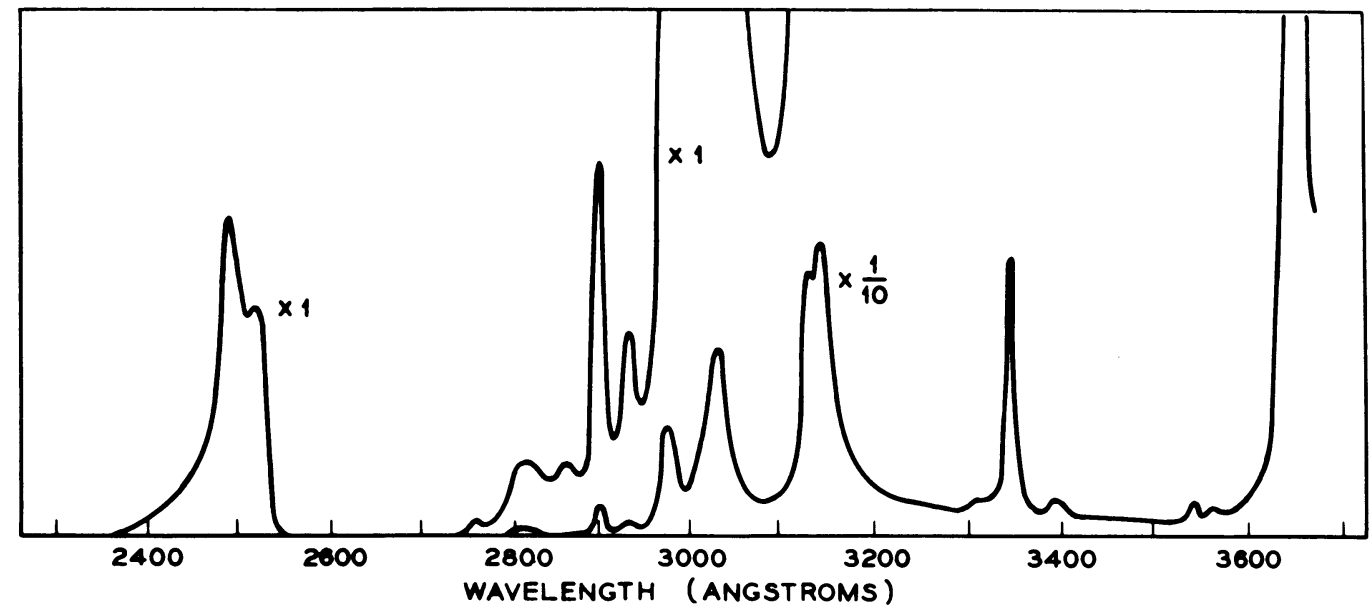

FIGURE 11

Spectral output of OSRAM 500 watt high pressure mercury lamp.

equilibrated at 75 per cent $\mathrm{R} . \mathrm{H}$. for several days, we estimate the DNA absorbed $\sim 5.4 \times 10^{19}$ photons. Using an electronic integrator and several independent methods for calibrating the sensitivity of the ESR spectrometer, we calculate these samples contained $6 \times 10^{16}$ paramagnetic damage centers before annealing. By counting only those spins which contribute to the far wings and extrapolating by use of the theoretical spectrum, it is easy to calculate the fraction of all centers which are thymine radical centers. For each thymine center there is approximately one other nonthymine paramagnetic center for a total of $3 \times 10^{16}$ thymine centers. There is approximately one thymine center per 2000 absorbed photons, for a quantum efficiency of $5 \times 10^{-4}$.

These values of quantum yield, while quite reproducible under the same conditions, can be several times larger or smaller depending upon the dose rate and the sample temperature. It is very likely that at high radiation doses (i.e., $0.15 \mathrm{~W}$ ), the temperature of the DNA fibers was greater than the nominal $77^{\circ} \mathrm{K}$. Using three copper screens to attenuate the light by a factor of 20 (i.e., to $0.0075 \mathrm{~W}$ ), a DNA sample was irradiated for $90 \mathrm{~min}$ on each of two sides for a total exposure of $180 \mathrm{~min}$. The results are shown in Figure 12. This sample was then raised to room temperature for $30 \mathrm{~min}$ to anneal away the thymine radical and then cooled to $77^{\circ} \mathrm{K}$ and irradiated for $4.5 \mathrm{~min}$ on each of two sides, total exposure $9.0 \mathrm{~min}$, without the three copper screens. The results of previous experiments had demonstrated that after this annealing procedure, for the same conditions of irradiation, the damage center was reproduced to within $\sim 30$ per cent. In this case, for the same dosage, but 20 times more intensity, the thymine radical signal was $3 \sim 4$ times larger.

A similar experiment was done at $195^{\circ} \mathrm{K}$ by immersing the sample tube in a solution of dry-ice and methanol. The results of $180 \mathrm{~min}$ irradiation at $0.0075 \mathrm{~W}$ and $9.0 \mathrm{~min}$ at $0.15 \mathrm{~W}$ are shown. Both of these signals are considerably larger than the $180 \mathrm{~min}$ exposure at $0.0075 \mathrm{~W}$ done at $77^{\circ} \mathrm{K}$. We further observed that if the Corning 7-54 filter was removed and the only filter was $4 \mathrm{~cm} \mathrm{of} \mathrm{H}_{2} \mathrm{O}$, the radicals produced at $77^{\circ}$ and $195^{\circ} \mathrm{K}$ were identical. A possible conclusion is that near $77^{\circ} \mathrm{K}$ the efficiency for radical production is a function of temperature but by $195^{\circ} \mathrm{K}$ the temperature dependence had vanished. Of course, 

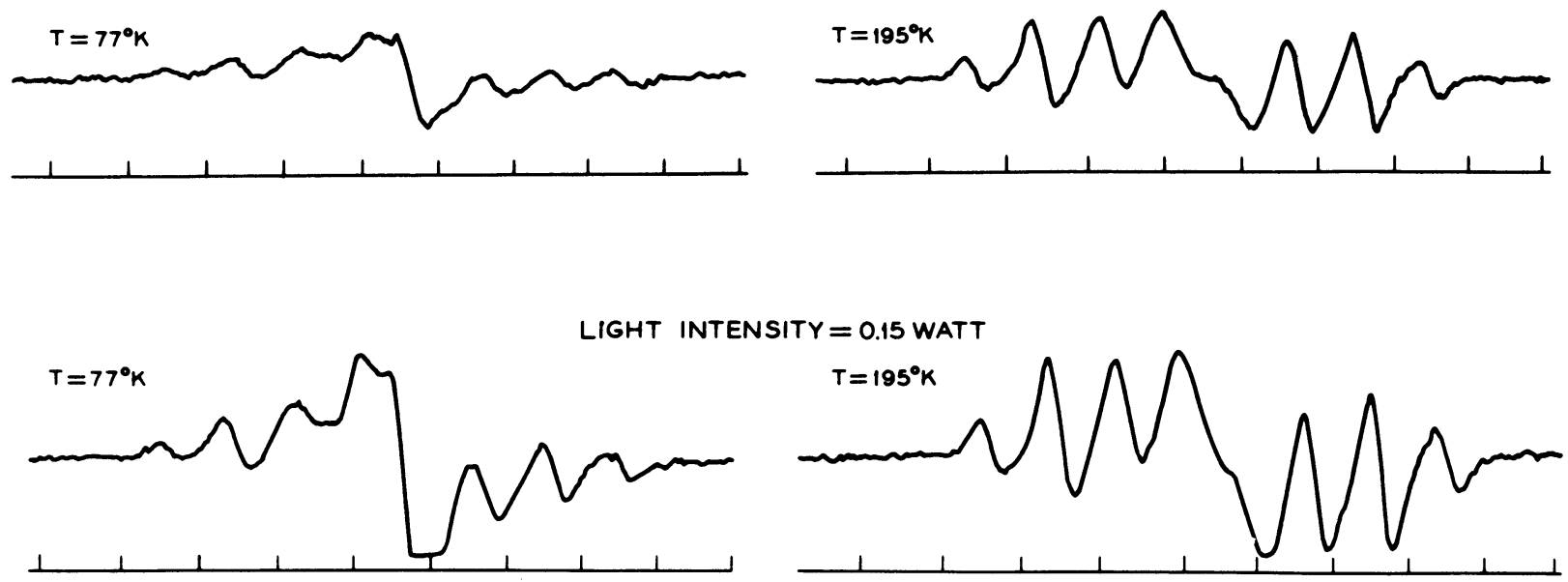

FIGURE 12

In all four traces the total dosage was the same, i.e., $8 \times 10^{8}$ ergs or $\sim 10^{7} \mathrm{ergs} / \mathrm{mm}^{2}$, since with the weaker light the exposure was $180 \mathrm{~min}$ and with the stronger light $9.0 \mathrm{~min}$. Notice first the larger signal obtained for the stronger light at $77^{\circ} \mathrm{K}$ as compared to the weak light and notice the increase in thymine radical from $77^{\circ} \mathrm{K}$ to $195^{\circ} \mathrm{K}$ in both cases.

other possible explanations exist. The temperature dependence, however, is the simplest explanation and should be in vestigated further before serious consideration is given to any other. In summary, the quoted quantum efficiency of $5 \times 10^{-4}$ is approximately correct for temperatures between $77^{\circ}$ and $195^{\circ} \mathrm{K}$, since lower dose rates would decrease the yield while the higher temperature would increase it, in both casus by a factor of $\sim 3$.

An attempt to determine the action spectrum is shown in Figure 13. The spectra illustrated were created by $2967 \AA$ light produced by an interference filter with a half width of $100 \AA$. The dose rate was $\sim 0.005 \mathrm{~W}$. There is a center line which appears at low dosages but does not grow linearly with time. At the highest dosage, $54 \mathrm{~W}-\mathrm{sec}$., a thymine signal, is seen which has almost the same intensity as the thymine signal produced after $81 \mathrm{~W}-\mathrm{sec}$ irradiation through the Corning 7-54 filter, attenuated by wire screens to a dose rate of $0.0075 \mathrm{~W}$. This experiment shows that $2967 \AA$ light is as effective as the other light between 2400 and $4000 \AA$ in forming radicals. Because even less light was available at other wavelengths within the DNA absorption band, it was not possible to measure radical formation as a function of wavelength.

It was possible, in a separate experiment, to compare the efficiency of wavelengths greater than $3200 \AA$ with those less than $3200 \AA$ by measuring the signals produced by equal intensities of light passed by a $\mathrm{CuSO}_{4}$ filter and by a $\mathrm{NiSO}_{4}$ filter. Intensities were measured with an RCA 935 phototube. The ESR signals with the $\mathrm{NiSO}_{4}$ filter were comparable to those obtained with the Corning 7-54 filter. With the $\mathrm{CuSO}_{4}$ filter the radiation produced no detectable ESR signal. On the other hand, when the full intensity of the lamp was passed through the $\mathrm{CuSO}_{4}$ filter, a weak thymine signal was produced. Because the $\mathrm{CuSO}_{4}$ filter only passes light with $\lambda>3200 \AA$, it appears as though DNA can be damaged by radiation of wavelength longer than $3200 \AA$, although about ten times less efficiently than with $\lambda<3200 \AA$. Possibly, this is true only for the optically dense DNA fibers which can absorb significant fractions of the incident radiation far past the normal absorption edge (i.e., $\lambda \approx 3000 \AA$ ). A second possibility is that the thymine radical can be formed by photodamage of a nonmagnetic damage center in DNA which has originally been produced by shorter wavelengths. In other words, the primary radiation in the DNA absorption band could produce a photo product which would absorb longer wavelength radiation. In support of this possibility we have observed that exposure of a moist DNA sample to 10 mrad $\gamma$-irradiation increases the quantum efficiency for subsequent U.V. production by light of $\lambda>3200 \AA$ of paramagnetic centers by a 


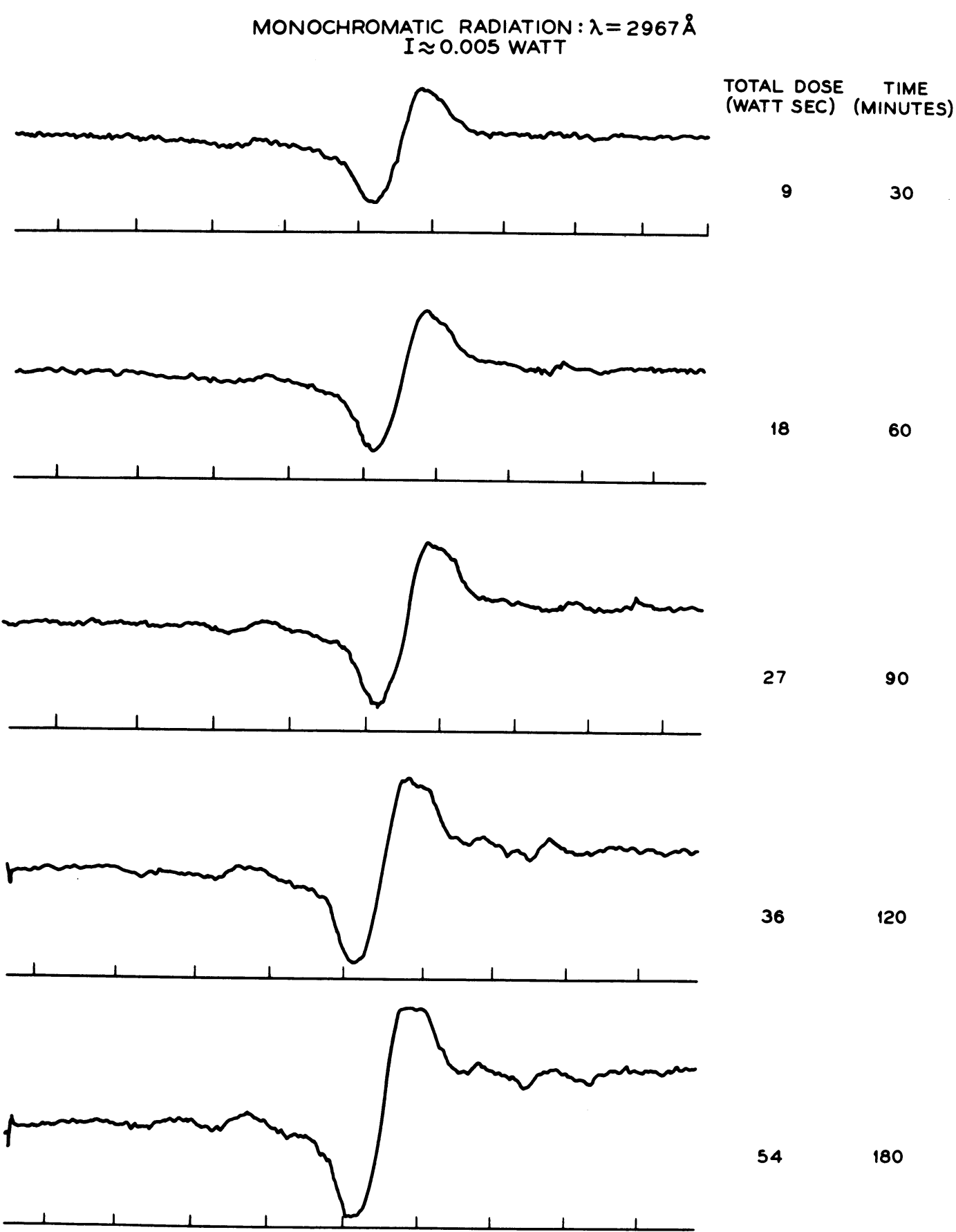

FIGURE 13

Effects of irradiating with $2967 \AA$ light showing how the central line appears first and the thymine afterwards. Note that the thymine is quite comparable with that shown in the upper left corner of Figure 12 where nonfiltered light was used at about the same intensity for about the same total dose.

factor of $\sim 3$. The $y$-irradiation itself is done at room temperature and in moist samples it produces no detectable paramagnetic centers.

In addition to the quantum yield which is quoted above, another relevant figure is the fraction of thymine converted to the thymine radical. Thin films of DNA were laid down upon flat quartz plates. Their 
weights ranged from $0.030 \mathrm{mg} / \overline{\mathrm{cm}}^{2}$ to $1.0 \mathrm{mg} / \overline{\mathrm{cm}}^{2}$ after they were equilibrated at 75 per cent R.H. The sample areas were $\sim 0.4 \overline{\mathrm{cm}}^{2}$. They were irradiated at $77^{\circ} \mathrm{K}$ with the OSRAM lamp plus $7-54$ filter set at full intensity and the number of spins measured as a function of dose. The amount of DNA present was determined from the optical density of similar films to be 0.60 of the total weight. This agreed with the findings of Langridge et al. [19]. The results were that three films with total weights of 180,200 and 750 $\mu \mathrm{g}$ gave 5.7, 5.6 and 3.5 per cent conversion of their thymines to free radicals. These fractional yields of radicals leveled off at dosages of $\approx 10^{7} \mathrm{erg} / \mathrm{mm}^{2}$. The samples had optical densities ranging from 5 to 20 at $2600 \AA$. However, judging from their responses to irradiation on both sides, except for the heaviest sample, they were all optically thin to damage by the OSRAM lamp, and the heavy sample was far from being optically thick. Therefore, we conclude that the samples absorb at least one order of magnitude less light from the lamp than indicated by their optical densities at $2600 \AA$. This is also confirmed by a comparison of the ESR intensity from a $5 \mathrm{mg}$ sample with $\sim 10^{7} \mathrm{ergs} / \mathrm{mm}$ whose total area was $\sim 0.4 \overline{\mathrm{cm}}^{2}$ with the signal from these films at the same dose and with the same area. The $5 \mathrm{mg}$ sample gave a signal which was 20 times larger, indicating that one could think of it as composed of about twenty layers, each comparable with the film, within which radicals were generated. This concept resolves a paradox, i.e., why the thymine dimer converts $\sim 5$ per cent of the thymines in calf thymus DNA to dimers at $\sim 10^{5}$ ergs/ $\mathrm{mm}^{2}$ of $2600 \AA$ light while the radical requires $\sim 10^{7} \mathrm{ergs} / \overline{\mathrm{mm}}^{2}$ to convert the same fraction even though their quantum yields are approximately equal. The answer is that the small cavity of the ESR spectrometer forced us to use samples with a small area. In order to produce enough radicals in these small areas we needed a high intensity light which penetrated to a considerable depth. For low doses of biological interest, however, the relevant figures are the quantum yields and in this respect, the thymine radical is produced almost efficiently as the dimer.

\section{Effects of Paramagnetic Metal lons}

Figure 14 shows the effects of two paramagnetic metal ions on the efficiency of producing the thymine damage center. $\mathrm{Cu}^{++}$and $\mathrm{Co}^{++}$were introduced in the ratio of one metal ion to ten phosphates and were slowly sprayed in to prevent aggregation [21]. The $\mathrm{Cu}^{++}$ion resonance overlaps the thymine resonance and for comparison $\mathrm{Cu}^{++}$-DNA spectrum is shown before irradiation. The $\mathrm{Co}^{++}$ion has a very broad resonance and does not interfere with observation of the thymine center. Three separate pairs of $\mathrm{Cu}^{++} \mathrm{DNA}$ and metal free DNA all gave a thymine signal ranging from one half to one sixth as great in the $\mathrm{Cu}^{++}$sample as in the control sample. The reduced thymine intensity in the $\mathrm{Co}^{++}$-DNA sample was also about six times smaller than in the control. This result is qualitatively reproducible when one obtains a homogenous distribution of $\mathrm{Co}^{++}$ions on the DNA. It is in agreement with the findings of Beukers and Berends [22] who have reported a reduction in the amount of stable photoproducts of pyrimidines in the presence of paramagnetic metal ions.

Figure 15 demonstrates an interaction between the $\mathrm{Co}^{++}$-DN A at $-25 \mathrm{db}$ and at $-5 \mathrm{db}$. In this sample, the higher power does not give microwave saturation. The fast relaxing $\mathrm{Co}^{++}$is relaxing the thymine spins via a cross-relaxation mechanism [23] so they do not saturate. It would be interesting to study the dependence of this effect on $\mathrm{Co}^{++}$concentration since it is conceivable that at low concentrations the $\mathrm{Co}^{++}$will not affect the quantum efficiency for production of the radical but still might shorten the paramagnetic relaxation time enough so that the thymine will not saturate. An increase in $20 \mathrm{db}$ of power decreases the minimum detectable number of thymine spins by a factor of 10 , and might make it possible to detect radicals produced by weaker monochromatic light sources. In this way the action spectrum for the thymine damage might be measured. 
(a)

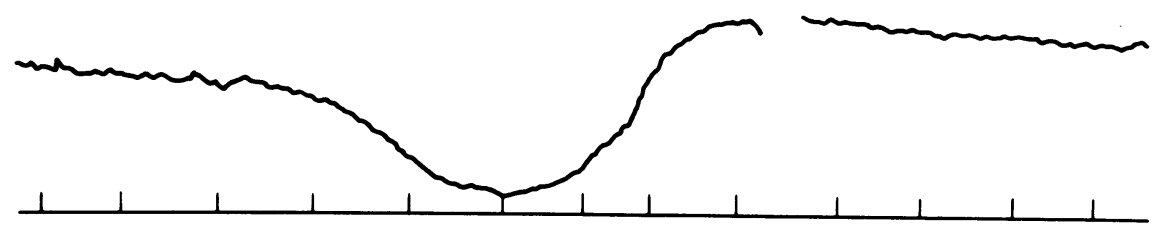

(b)

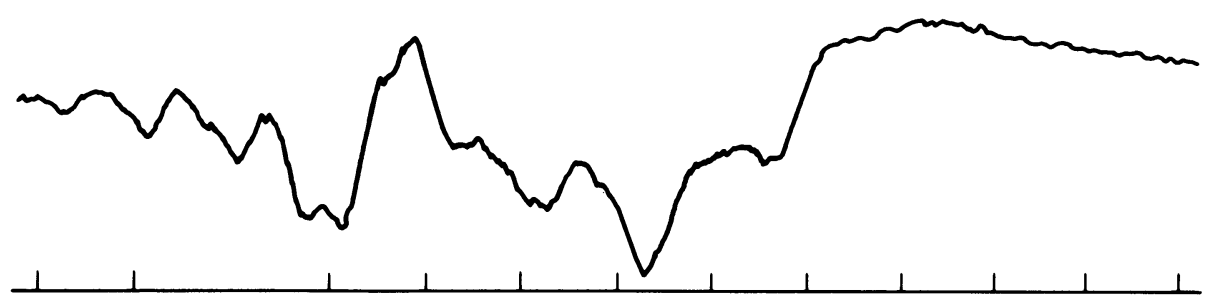

(c)
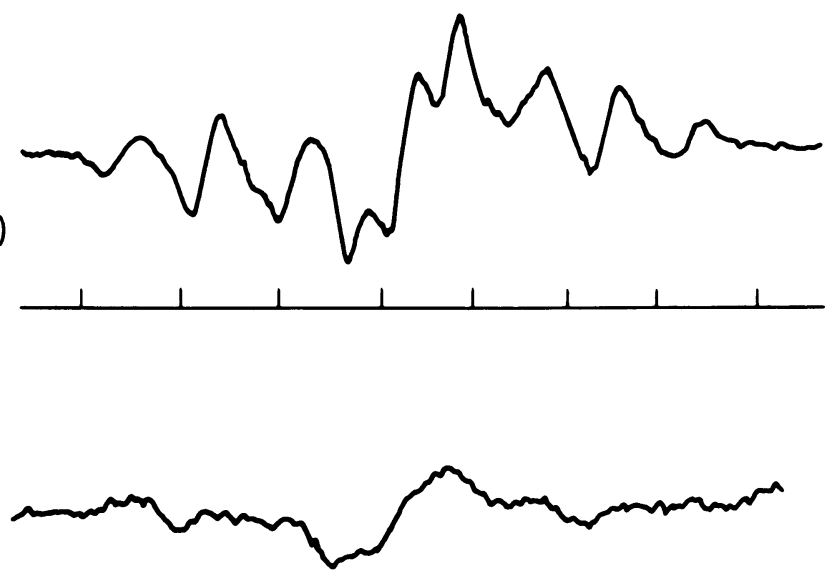

(d)

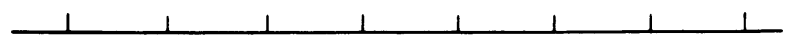

FIGURE 14

In (a) the $\mathrm{Cu}^{++}$resonance is observed in moist DNA before irradiation. In (b), after irradiation, the thymine resonance appears but it is consistently several times weaker (the reduction ranges from two, as shown, to six) than the control DNA sample in (c). The Co ${ }^{++}$doped sample in (d) consistently shows a considerable reduction in the amount of thymine. 

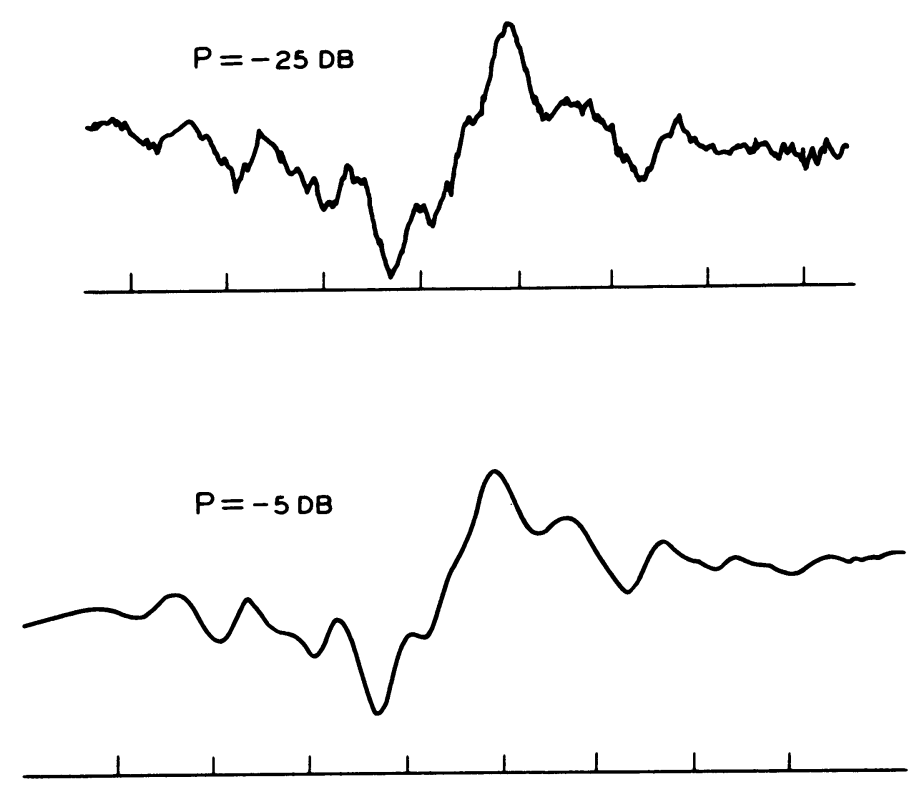

FIGURE 15

The effect of $\mathrm{Co}^{++}$upon the spin lattice relaxation time of the thymine radical in moist ( 75 per cent $\mathrm{RH}$ ) DNA is shown in this comparison between two power levels. In the absence of $\mathrm{Co}^{++}$ the signal begins to saturate at $-25 \mathrm{db}$ and increasing the power does not increase the signal. Here the signal increases ten times (the gain is ten times lower in the lower figure) upon increasing the power presumably because of cross relaxation to the $\mathrm{Co}^{++}$.

\section{Discussion of Results}

What have we definitely proven about irradiated DNA? How do our findings fit in with other investigations, by different techniques of radiation damage in DNA? What unresolved and sometimes even contradictory findings do we have which require further work to be understood.

We have proven that the hydrogen addition product of thymine is created in DNA by irradiation. It accounts for a considerable portion of the radicals formed, ranging from $\sim 10$ to $\sim 80$ per cent, depending upon conditions. By separate deuteration of the methyl and of the methylene group we have proven the structure of this radical in DNA and thymine. The additional hydrogen has been shown to come from water or exchangeable protons. Increasing the moisture content of the DNA increases the amount of thymine radical. The same amount of thymine radical is formed in native and denatured DNA samples, providing that they contain the same amount of moisture. Radiation between 2400 and $3200 \AA$ is considerably more effective than radiation with $\lambda>3200 \AA$ in creating damage centers. In addition to the thymine radical, four or five additional resonances have been characterized in irradiated DNA and suggestions made as to how to identify them. It has been shown that increasing the temperature of the DNA during irradiation from $77^{\circ}$ to $195^{\circ} \mathrm{K}$ increases the yield of thymine radical, while in a possibly related series of experiments it has been shown that increasing the light intensity at $77^{\circ} \mathrm{K}$ increases the number of radicals for a constant total dose. The quantum yield for creating thymine radicals is $5 \times 10^{-4}$ radicals per photon absorbed and this number can vary by a factor of five in either direction, depending upon temperature, humidity and light intensity. Increasing temperature, humidity or light intensity increases the quantum efficiency. 
What is the connection between this radical and stable photodamage products of thymine, in particular the thymine dimer [22] which has been shown [24-26] to be an important cause of damage? At the beginning, let us state we do not know what stable photoproduct, if any, this radical goes on to form. The one experiment which has been tried in order to identify the stable photoproduct has given negative results. Prof. A. Wacker kindly irradiated dry DNA at low temperatures, as we do in order to create these radicals, and then he dissolved the DNA in tritiated water. Subsequent hydrolysis followed by chromatographic analysis showed no differences from the unirradiated control. In other words, although water destroys the thymine radical, it does not do so by adding to it. Now that we are able to introduce deuterium atoms into the double bonds, it should be possible to add the tritiated water before irradiation and to analyze chemically for the stable photo product which incorporates the tritium. Wacker [5] has shown that there are several thymine photoproducts in addition to the dimer formed. Furthermore, at the high doses $>10^{6}$ ergs/ $\overline{\mathrm{mm}}^{2}$ used in our experiments, several of these other products are quite abundant, each containing about three per cent of the original thymine. As the dosage was increased, the amount of these other damage products became approximately equal to the amount of dimer.

We do not have any reason to believe that the thymine free radical is a precursor of the thymine dimer. The dimer, it will be recalled, forms a four membered saturated cyclobutane ring by opening up the 5-6 double bond of two adjacent thymines. The free radical is also formed by adding to that double bond but there the similarity probably stops. The strongest evidence for a distinction between the thymine radical and the dimer is found in crystals of $\mathrm{N}$-methyl thymine. These experiments were originally performed by A. Kwiram at the California Institute of Technology and have been repeated in our laboratory. Irradiation of $\mathrm{N}$-methyl thymine polycrystalline samples by U.V. light does not produce the thymine radical, while irradiation with X-rays or $\gamma$-rays does. From the crystal structure [27] of $\mathrm{N}$-methylthymine, it is known that all the thymines are located so that the center of each $5-6$ double bond is $3.7 \AA$ from another. This is within the range which has been shown by Cohen and Schmidt [28] to be suitable for dimerization upon photo excitation. Furthermore, Stewart [29] has reported that $>44$ per cent of the molecules in N-methyl thymine are dimerized by U.V. light. From this behavior we draw the tentative conclusion that when thymines are adjacent to each other in DNA and, therefore, in the proper position to dimerize upon U.V. excitation they do, while those that cannot dimerize either because they are separated or because a hydrogen atom has been added to the double bond may go on to form the thymine radical.

Because the thymine dimer has been shown to constitute a considerable fraction of DNA damage (the percentage ranges from less than ten per cent to more than eighty under different conditions [30]), it provides a relevant comparison for the abundance and quantum efficiency of formation of the thymine radical. First, as mentioned, after very high doses of $\sim 10^{7} \mathrm{ergs} / \overline{\mathrm{mm}}^{2}$ of light, which is mainly $2900 \AA \rightarrow 3000 \AA$, about 5 per cent of the thymines in calf thymus DNA are converted to radicals. This agrees, within the limits of our uncontrolled experimental variables, with the value of $\sim 6$ per cent converted to the dimer at U.V. doses about an order of magnitude lower. However, our measurements have required this heavy dose because of the relative insensitivity of the ESR detection scheme and the spectral characteristics of the light source.

A second and more relevant comparison is the quantum efficiency of formation. Deering and Setlow [31] report a quantum yield of 0.01 for dithymidylic acid while we have measured a value of $5 \times 10^{-4}$ for thymine radical formation in calf thymus DNA. To estimate approximately the quantum yield of dimers in this DNA where $(A+T) /(G+C) \sim 1$, we consider that one quarter of the light is absorbed by thymine and that each thymine has a probability of $\frac{1}{4}+\frac{1}{4}=\frac{1}{2}$ of having at least one thymine near neighbor. Therefore, about one half of the thymines can form dimers or, assuming the same efficiency for DNA as for the dithymidylic acid, there should be a quantum yield of $\approx 10^{-3}$ which is about twice as large as for the thymine radical. Since radical yields can vary with conditions, these values are close enough to show that the two are formed with comparable efficiency. In fact, since our quantum yield values come from the high dose region of the growth curve where saturation is taking place, it is clear that $5 \times 10^{-4}$ is a lower limit for the thymine radical.

As for the unanswered questions, we feel that the most important concerns the stable photo product formed from the radical, a problem which can be answered by chemical approaches as outlined above. 
Once settled, it will provide the incentive to clarify the uncertainties which surround our knowledge of this system.

We would like to express our gratitude to W. M. Walsh, Jr. for his early work on this problem and for his comments on the manuscript.

\section{References}

1. F. H. C. CRICK and J. D. WATSON, Proc. Roy. Roc. A 223, 80, (1954).

2. H. J. MÜLlER, Amer. Nat. 60, 192 (1926).

3. O. T. AVERY, C. M. McCLEOD and M. McCARTY, J. Exp. Med. 79, 137 (1944).

4. K. G. ZIMMER and A. MULLER, to be published in Current Topics in Radiation Research.

5. A. WACKER, Progress in Nucleic Acid Research (Edited by J. N. DAVIDSON and W. E. COHN) Academic Press, Vol. I, p. 369, New York (1963).

6. K. C. SMITH, Photobiology: Action of Light on Living Materials (Edited by A. C. GIESE) Academic Press, New York (1963).

7. R. SALOVEY, R. G. SHULMAN and W. M. WALSH, JR., J. Chem. Phys. 39, 839 (1963).

8. J. EISINGER and R. G. SHULMAN, Proc. Nat. Acad. Sci. 50, 694 (1963).

9. A. EHRENBERG, L. EHRENBERG and G. LÖFROTH, Nature, Lond. 200, 376 (1963).

10. H. SHIELDS and W. GORDY, Proc. Nat. Acad. Sci. 45, 269 (1959).

11. W. M. WALSH, JR., R. G. SHULMAN and R. D. HEIDENREICH, Nature, Lond. 192, 1041 (1961).

12. S. OHNISHI, T. TANEI, and I. NITTA, J. Chem. Phys. 37, 2402 (1962).

13. H. FISCHER, J. Chem. Phys. 37, 1094 (1962).

14. R. W. FESSENDEN and R. H. SCHULER, J. Chem. Phys. 38, 773 (1963).

15. A. L. KWIRAM, private communication.

16. J. MARMUR, J. Mol. Biol. 3, 208 (1961).

17. M. FALK, K. A. HARTMAN, JR. and R. C. LORD, J. Amer. Chem. Soc. 85, 391 (1963).

18. R. E. FRANKLIN and R. G. GOSLING, Acta Cryst. 6, 673 (1953).

19. R. LANGRIDGE, H. R. WILSON, C. W. HOOPER, M. H. F. WILKINS and L.D. HAMILTON, J. Mol. Biol. 2, 19 (1960).

20. A. EHRENBERG, private communication.

21. W. M. WALSH, JR., L. W. RUPP, JR. and B. J. WYLUDA, Symposium on Paramagnetic Resonance (Edited by W. LOW), Vol. 2, p. 836, Academic Press, New York (1963).

22. R. BEUKERS and W. BERENDS, Biochim. Biophys. Acta 49, 181 (1961).

23. N. BLOEMBERGEN, S. SHAPIRO, P. S. PERSHAN and J. O. ARTMAN, Phys. Rev. 114, 445 (1959).

24. A. WACKER, H. DELLWEG and E. LODEMANN, Angew. Chem. 73, 64 (1961).

25. R. B. SETLOW and J. K. SETLOW, Proc. Nat. Acad. Sci 48, 1250 (1962).

26. D. L. WULFF, Biophys. J. 3, 335 (1963).

27. K. HOOGSTEEN, Acta Cryst. 16, 28 (1963).

28. M. D. COHEN and G. M. J. SCHMIDT, Reactivity of Solids (Edited by J. H. DeBOER) Elsevier, Amsterdam (1963).

29. R. F. STEWART, Biochim. Biophys. Acta 75, 129 (1963).

30. R. B. SETLOW, private communication.

31. R. A. DEERING and R. B. SETLOW, Biochim. Biophys. Acta 68, 526 (1963). 